\title{
Influência de cristalizantes e cinza volante na durabilidade de concreto exposto ao ataque externo por ácido sulfúrico biogênico em um reator UASB de uma ETE
}

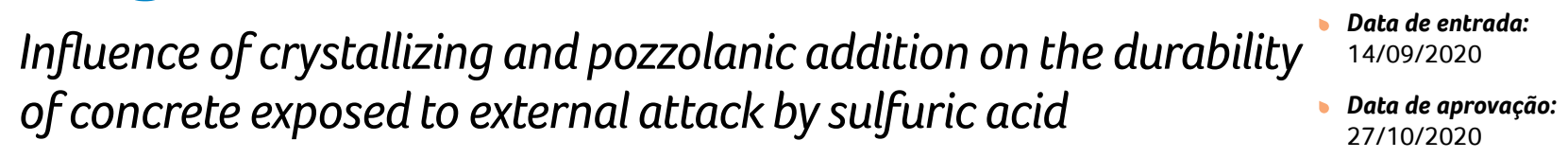

ORCID ID

Godinho JP (D) https://orcid.org/0000-0003-2948-8639

Medeiros MHF (D) https://orcid.org/0000-0003-3112-9715

\section{Resumo}

As estações de tratamento de esgoto são exemplos de estruturas submetidas a ambientes industriais altamente agressivos. Deste modo, o objetivo do estudo foi avaliar o efeito de cristalizantes comerciais e do silicato de sódio $\left(\mathrm{Na}_{2} \mathrm{SiO}_{3}\right)$ no aumento da durabilidade do concreto armado submetido ao ataque sulfúrico de origem biogênica em uma ETE e de origem química em laboratório. Para atingir esse objetivo, foram realizados diversos ensaios, como velocidade de degradação, variação de massa, profundidade de neutralização, velocidade de pulso ultrassônico, resistência à tração na flexão e à compressão. Ao final, pôde-se concluir que a velocidade de degradação e a perda de massa são menores nos concretos com cristalizantes e cinza volante e que esses dois ensaios são os mais confiáveis para avaliar a durabilidade em longo prazo de estruturas de concreto exposto ao ácido sulfúrico.

Palavras-chave: Concreto. Durabilidade. Ácido Sulfúrico Biogênico. Estação de Tratamento de Esgoto.

\section{Abstract}

Sewage treatment plants are examples of structures subjected to highly aggressive industrial environments. Thus, the aim of the study was to evaluate the effect of commercial crystallizers and sodium silicate $\left(\mathrm{Na}_{2} \mathrm{SiO}_{3}\right)$ in increasing the durability of reinforced concrete subjected to sulfuric attacks of biogenic origin in a TEE and of chemical origin in the laboratory. To achieve this objective, several tests were performed, such as degradation speed, mass variation, neutralization depth, ultrasonic pulse speed, flexural and compression tensile strength. In the end, we conclude that the speed of degradation and the loss of mass is lower in concretes with additions and that these two tests are the most reliable to evaluate the long-term durability of concrete structures exposed to sulfuric acid. Keywords: Concrete. Durability. Biogenic Sulfuric Acid. Sewage Treatment Plant.

\footnotetext{
${ }^{1}$ Universidade Federal do Paraná - Curitiba - Paraná - Brasil.

* Autor correspondente: jayson.godinho.engagmail.com.
} 


\section{INTRODUÇÃO}

Nas tubulações e estações de tratamento de esgoto sanitário (ETE), o líquido transportado possui vários compostos dissolvidos que são agressivos ao concreto das estruturas. Dentre eles, estão os compostos de enxofre que são facilmente oxidados por bactérias do gênero Thiobacillus e transformam esses compostos em ácido sulfúrico biogênico (PINTO; TAKAGI, 2007).

O ácido sulfúrico biogênico, em contato com o concreto, reage com o hidróxido de cálcio do mesmo, formando gipsita. Mas essa espécie desempenha somente papel secundário na degradação do concreto, pois a gipsita formada passa a reagir com o aluminato tricálcio hidratado (C3A), formando a etringita, que é muito mais prejudicial, pois é associada a uma expansão em torno de 7 vezes, ao ponto que a gipsita possui somente uma expansão em torno de 2 vezes (MONTENY et al., 2000).

Além disso, essas expansões geram tensões internas e deterioração da matriz do concreto, ocasionando o aparecimento de microfissuras, que podem gerar vias de corrosão por outros agentes e até mesmo chegar na armadura. Além dessas expansões, ocorre a dissolução do $\mathrm{C}-\mathrm{S}-\mathrm{H}$, influenciando na perda de resistência do concreto (HUSNI et al., 2012).

Em todo o mundo, os sistemas de tratamento de águas servidas municipais estão expostos à degradação do concreto por ácido sulfúrico biogênico, que tende a comprometer a integridade das estruturas, necessitando de dispendiosos reparos provocados por falhas prematuras da infraestrutura necessária ao tratamento de esgoto (MONTENY et al., 2000; DE BELIE et al., 2004).

Desse modo, estudos focados em entender o mecanismo de deterioração que envolve este ambiente agressivo ao concreto são importantes para o avanço da fronteira do conhecimento, oferecendo mais subsídios para o meio técnico produzir especificações de materiais mais adequados e capazes de gerar estruturas com elevada durabilidade, apesar da alta agressividade que ocorre nas estações de tratamento de esgoto.

Diante disso, o objetivo desse trabalho foi estudar o efeito de cristalizantes comerciais, silicato de sódio $\left(\mathrm{Na}_{2} \mathrm{SiO}_{3}\right)$ e cinza volante no aumento da durabilidade e elevação da vida útil do concreto armado submetido ao ataque por sulfúrico de origem biogênica em ETEs e de origem química em laboratório.

\section{MATERIAIS E MÉTODOS}

\subsection{Materiais}

O cimento utilizado foi o CP V-ARI com substituição de $35 \%$ da massa total de cimento por cinza volante. A caracterização química dos aglomerantes está representada na Tabela 1 . O agregado miúdo é uma areia natural, oriunda da região metropolitana de Curitiba. Esse agregado apresentou uma distribuição granulométrica dentro da zona utilizável de acordo com a NBR 7211 (ABNT, 2009) e módulo de finura igual a 1,78 de acordo com a NBR NM 248 (AMN, 2003). O agregado graúdo é proveniente da região metropolitana de Curitiba e tem origem basáltica. Ele pode ser classificado dentro da zona granulométrica $2,36-9,50 \mathrm{~mm}$ e possui diâmetro máximo característico (DMC) igual a $9,50 \mathrm{~mm}$. A massa específica do agregado miúdo foi de $2,30 \mathrm{~g} / \mathrm{cm}^{3}$, e a do agregado graúdo foi de $2,57 \mathrm{~g} / \mathrm{cm}^{3}$. Os cristalizantes comerciais não tiveram suas características químicas e a composição disponibilizadas pelos fabricantes, mas a sua coloração é acinzentada e possue, uma textura em pó. $\mathrm{O}$ silicato de sódio neutro $\left(\mathrm{Na}_{2} \mathrm{SiO}_{3}\right)$ tem uma densidade a $25^{\circ} \mathrm{C}$ entre 1,39 e $1,42 \mathrm{~g} /$ $\mathrm{cm}^{3}$, uma relação $\left(\mathrm{SiO}_{2}\right) /\left(\mathrm{Na}_{2} \mathrm{O}\right)$ entre 3,27 e 3,31 e um teor de água entre 61,0 e 63,0\%. 
Tabela 1 - Propriedades químicas do cimento CP V-ARI e da cinza volante.

\begin{tabular}{|c|c|c|c|c|c|c|c|c|c|}
\hline \multirow[b]{2}{*}{ Aglomerante } & \multicolumn{9}{|c|}{ Composição química (\%) } \\
\hline & $\mathrm{CaO}$ & $\mathrm{SiO}_{2}$ & $\mathrm{Al}_{2} \mathrm{O}_{3}$ & $\mathrm{Fe}_{2} \mathrm{O}_{3}$ & MgO & $\mathrm{SO}_{3}$ & $\mathrm{~K}_{2} \mathrm{O}$ & $\begin{array}{l}\text { Demais } \\
\text { Óxidos }\end{array}$ & $\begin{array}{l}\text { Perda ao } \\
\text { Fogo (\%) }\end{array}$ \\
\hline $\begin{array}{l}\text { Cimento } \\
\text { CPV-ARI }\end{array}$ & 62,75 & 19,2 & 4,19 & 2,85 & 2,54 & 3,04 & 1,68 & 0,25 & 3,5 \\
\hline Cinza Volante & 0,29 & 54,84 & 19,88 & 5,37 & 0,59 & 0,30 & 3,00 & 1,78 & 1,26 \\
\hline
\end{tabular}

\subsection{Moldagem dos corpos de prova}

O traço adotado foi 1: 1,9: 2,47 (cimento, areia, brita), e a relação água/aglomerante 0,45 , com abatimento do tronco de cone de $8 \pm 2 \mathrm{~cm}$. Na proporção de mistura foi utilizado um aditivo superplastificante à base de policarboxilato. Esses parâmetros são semelhantes aos aplicados na construção de uma Estação de Tratamento de Esgoto (ETE) na cidade de Ponta
Grossa-PR. O adensamento foi realizado em mesa vibratória por 10 segundos, sendo o preenchimento dos moldes feito em um camada de concreto de acordo com a NBR 5738 (ABNT, 2016). Foram moldadas cinco formulações (com base no tipo de aglomerante e cristalizantes), sendo elas apresentadas na Tabela 2. A adição de $1 \%$ dos cristalizantes foi com base na massa do aglomerante.

Tabela 2 - Formulações dos cinco diferentes concretos.

\begin{tabular}{|c|c|c|c|c|}
\hline \multicolumn{5}{|c|}{ Traço unitário: 1: 1,9: 2,47 (cimento, areia, brita) com relação água/aglomerante $=0,45$} \\
\hline \multicolumn{5}{|c|}{ Teor de aditivo superplastificante adicionado à mistura para atingir o abatimento especificado (\%) } \\
\hline V & $\mathbf{R}$ & M & $\mathbf{P}$ & $\mathbf{S}$ \\
\hline \multicolumn{5}{|c|}{ Cimentos CPV-ARI com 35 \% de substituição de sua massa total por cinza volante } \\
\hline $\begin{array}{c}\text { Cimento CP V-ARI sem } \\
\text { substituição por cinza volante }\end{array}$ & $\begin{array}{l}\text { (Referência) Sem adição de } \\
\text { cristalizantes }\end{array}$ & $\begin{array}{c}\text { Adicionado } 1 \% \text { de } \\
\text { cristalizante comercial } 1\end{array}$ & $\begin{array}{c}\text { Adicionado } 1 \% \text { de } \\
\text { cristalizante comercial } 2\end{array}$ & $\begin{array}{l}\text { Adicionado } 1 \% \text { de solução } \\
\text { de silicato de sódio neutro } \\
\left(\mathrm{Na}_{2} \mathrm{SiO}_{3}\right)\end{array}$ \\
\hline $0,12 \%$ & $0,13 \%$ & $0,18 \%$ & $0,15 \%$ & $0,20 \%$ \\
\hline
\end{tabular}

\subsection{Cura e ambientes de exposição}

A desforma dos corpos de prova foi feita $24 \mathrm{~h}$ após a moldagem. Em seguida, todas as amostras foram completamente imersas em um tanque com água saturada com cal à temperatura ambiente por 28 dias. Depois desse período, todos os corpos de prova passaram 90 dias por ciclos de molhagem e secagem semanal, sendo 7 dias imersos em tanque e 7 dias fora do tanque, para proporcionar melhor cristalização e preenchimento dos poros do concreto com os produtos cristalizantes aplicados conforme recomendação dos fabricantes. Após os ciclos de molhagem e secagem, todos os corpos de prova foram mantidos por 232 dias em um tanque com água saturada com cal à temperatura ambiente.

Por fim, as amostras foram divididas em três condições de exposição: 1 - tanque com água saturada com cal à temperatura ambiente do laboratório (Fig. 1A); 2 - canaleta de distribuição do esgoto sanitário tratado de um reator UASB de uma ETE operada na cidade de Curitiba-PR (Fig. 2); 3 - tanque em ambiente de laboratório com solução de ácido sulfúrico (Fig. 1B), com concentração inicial de 0,5\% e com manutenção do $\mathrm{pH}$ em um intervalo fixo, sendo que nesse ambiente os concretos ficaram parcialmente submersos, ficando seca apenas uma faixa de $10 \mathrm{~mm}$ do topo, como pode ser visto também na Fig. 3 . 

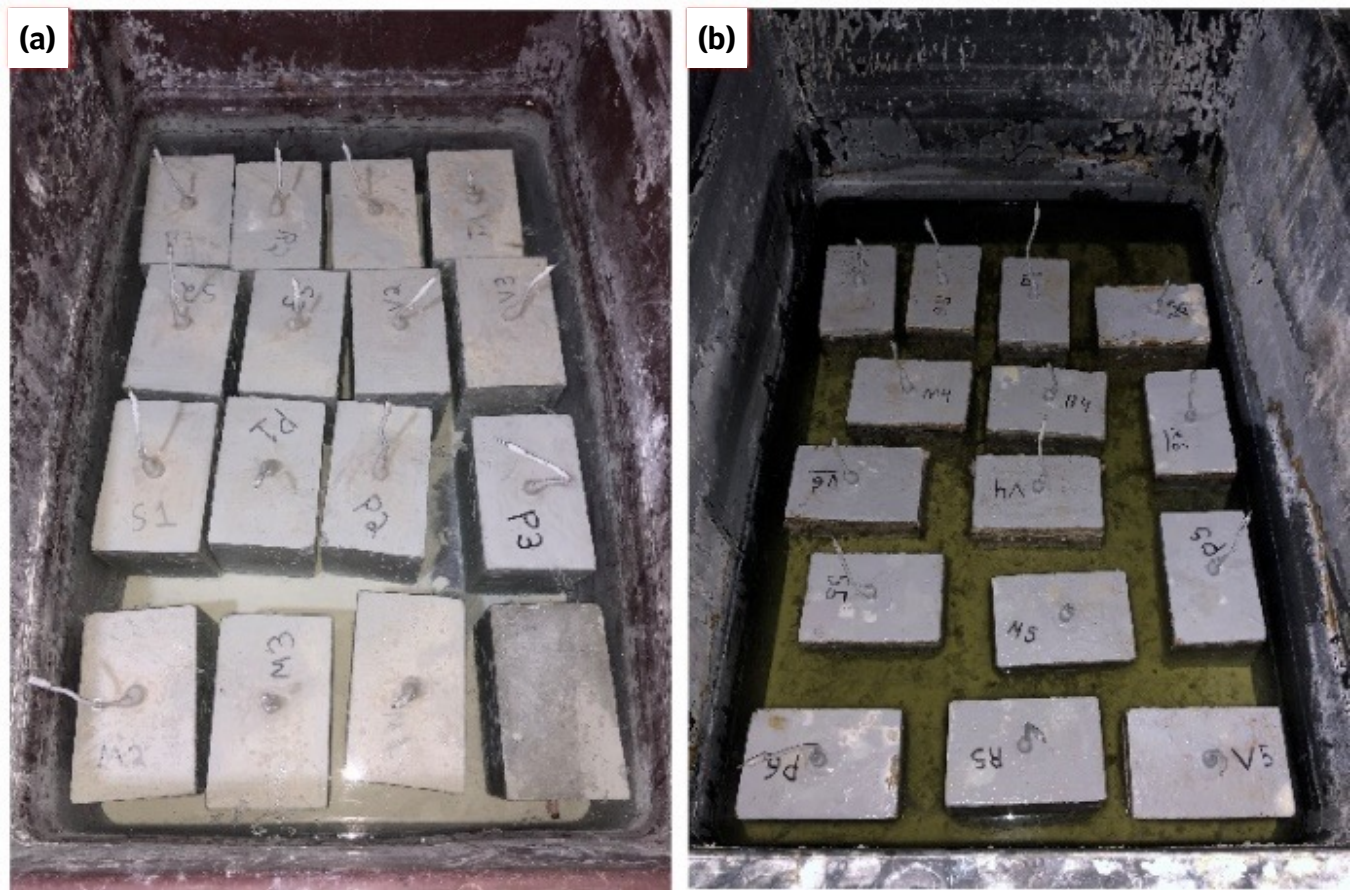

Figura 1 - Ambientes de exposição dos corpos de prova. a - Tanque com água saturada com cal; b - Tanque com solução de ácido sulfúrico.

$\mathrm{O}$ pH da solução contendo $0,5 \%$ de $\mathrm{H}_{2} \mathrm{SO}_{4}$ foi aferido quinzenalmente e mantido sempre em um intervalo de 2,00 $<\mathrm{pH}<3,50$, conforme recomendado por Eštokova et al., (2012) e Monteny; De Belie; Taerwe, (2003) de modo que houvesse uma faixa constante de agressividade do ataque por $\mathrm{H}_{2} \mathrm{SO}_{4}$. $\mathrm{O} \mathrm{pH}$ do ambiente contendo água saturada com cal também foi quinzenalmente aferido e mantido entre $11,00<\mathrm{pH}<12,00$.
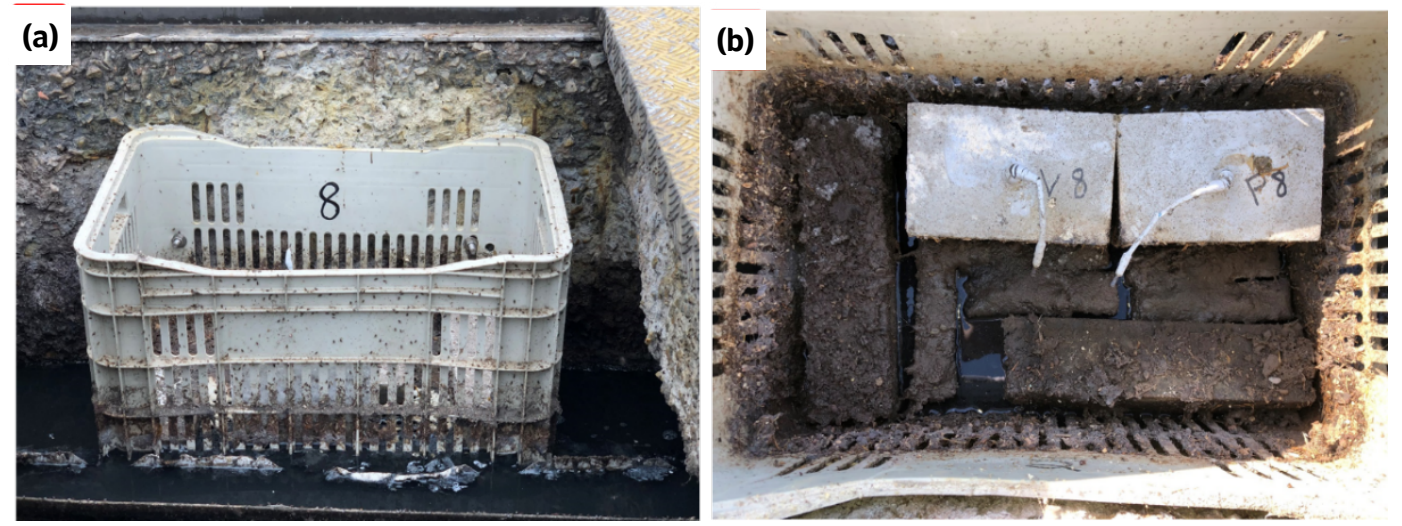

Figura 2 - Ambiente de exposição na canaleta de distribuição do esgoto sanitário tratado de um reator UASB de uma ETE operada na cidade de Curitiba-PR. a - vista frontal; b - vista superior. 
2.4 Velocidade de degradação e variação de massa

A velocidade de degradação (VD) dos corpos de prova de dimensões $17 \times 17 \times 11 \mathrm{~cm}$ foi medida com um paquímetro nas regiões de contato com o líquido (Fig. 3) e calculado com base na Eq. 1.

$$
V D=\frac{(\text { dimensão inicial }- \text { dimensão final }) / 2}{\text { número de meses }}
$$

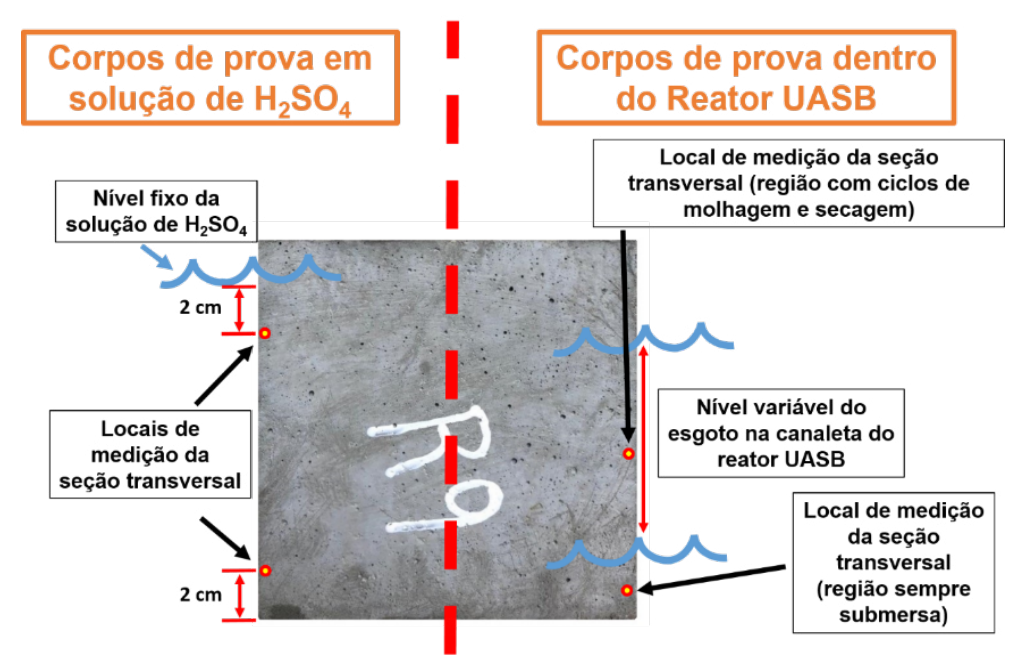

Figura 3 - Locais das medições da velocidade de degradação dos corpos de prova de concreto, indicados pelos círculos pequenos de borda vermelha e interior amarelo.

A variação da massa foi registrada com uma balança analítica de precisão $( \pm 0,01 \mathrm{~g})$. 0 cálculo da variação foi feito conforme a Eq. 2.

$$
\Delta \mathrm{M}=\frac{\mathrm{M}-\mathrm{M}_{\text {inicial }}}{\mathrm{M}_{\text {inicial }}} \times 100
$$

Onde: $\Delta M$ - variação de massa individual das barras, em porcentagem; $M$ - massa na idade considerada, em gramas; $M_{\text {inicial }}$ - massa inicial após 28 dias de cura em água saturada com cal, em gramas.

\subsection{Profundidade de neutralização}

Logo após as rupturas por tração na flexão dos corpos de prova prismáticos de concreto de dimensões $4 \mathrm{~cm} \times 4 \mathrm{~cm} \times 16 \mathrm{~cm}$, foi aspergida uma solução contendo $1 \%$ de fenolftaleína, $70 \%$ de álcool etílico e $30 \%$ de água destilada em quatro testemunhos de concreto. Esse procedimento é regido pelas normas BS EN 14630 (BSI, 2006) e RILEM CPC-18 (RILEM, 1994) e permite determinar a profundidade de neutralização com o auxílio de um paquímetro. Essa profundidade de neutralização representa a redução do $\mathrm{pH}$ de aproximadamente 12 , do concreto são, para abaixo da faixa de viragem da solução marcadora de fenolftaleína que é de aproximadamente $8,2 \leq \mathrm{pH} \leq 10,0$.

\subsection{Velocidade de pulso ultrassônico (VPU)}

Foram moldados corpos de prova de dimensões $4 \mathrm{~cm} \times 4 \mathrm{~cm} \times 16 \mathrm{~cm}$, para cada uma das cinco formulações de concreto, sendo ensaiados conforme preconiza a norma NBR 8802 (ABNT, 2019). Para tal, foram utilizados um aparelho digital de ultrassom da marca Proceq, modelo Pundit Lab, e gel de ultrassonografia para o contato dos transdutores (frequência de $250 \mathrm{kHz}$ e $28 \mathrm{~mm}$ de diâmetro) com a superfície do concreto, em consonância com o trabalho de Godinho et al. (2020). 


\subsection{Resistência à tração na flexão e à compressão uniaxial}

De modo a caracterizar a resistência mecânica à tração na flexão dos corpos de prova prismáticos de concreto de dimensões $4 \mathrm{~cm} \times 4 \mathrm{~cm} \times 16 \mathrm{~cm}$, foi utilizada uma prensa da marca Emic, modelo DL30000N, operada com taxa de carregamento de $1 \pm 0,15 \mathrm{MPa} / \mathrm{min}$. $O$ ensaio foi adaptado das normas NBR 13279 (ABNT, 2005) e ASTM C293 (ASTM, 2016). Nesse procedimento, as amostras de concreto ficam biapoiadas e recebem um carregamento central, no meio do vão, até a sua ruptura.

Tendo em vista que o rompimento das amostras no ensaio de resistência à tração na flexão dá origem a dois corpos de prova (aproximadamente $4 \mathrm{~cm} \times 4 \mathrm{~cm} \times 8 \mathrm{~cm}$ cada), utilizou-se um de- les para determinar a resistência à compressão uniaxial. Para tal, fez-se uso adaptado do procedimento descrito nas normas NBR 13279 (ABNT, 2005) e ASTM C349 (ASTM, 2014), empregando uma prensa da marca Emic, modelo DL30000N, operando a uma taxa de carregamento de $0,45 \pm 0,15 \mathrm{MPa} / \mathrm{s}$

\section{RESULTADOS E DISCUSSÕES}

\subsection{Caracterização do concreto antes da exposição aos ambientes agressivos}

Na Fig. 4 são apresentadas a evolução das resistências mecânicas e da velocidade de pulso ultrassônico (VPU) ao longo de 350 dias de idade do concreto.
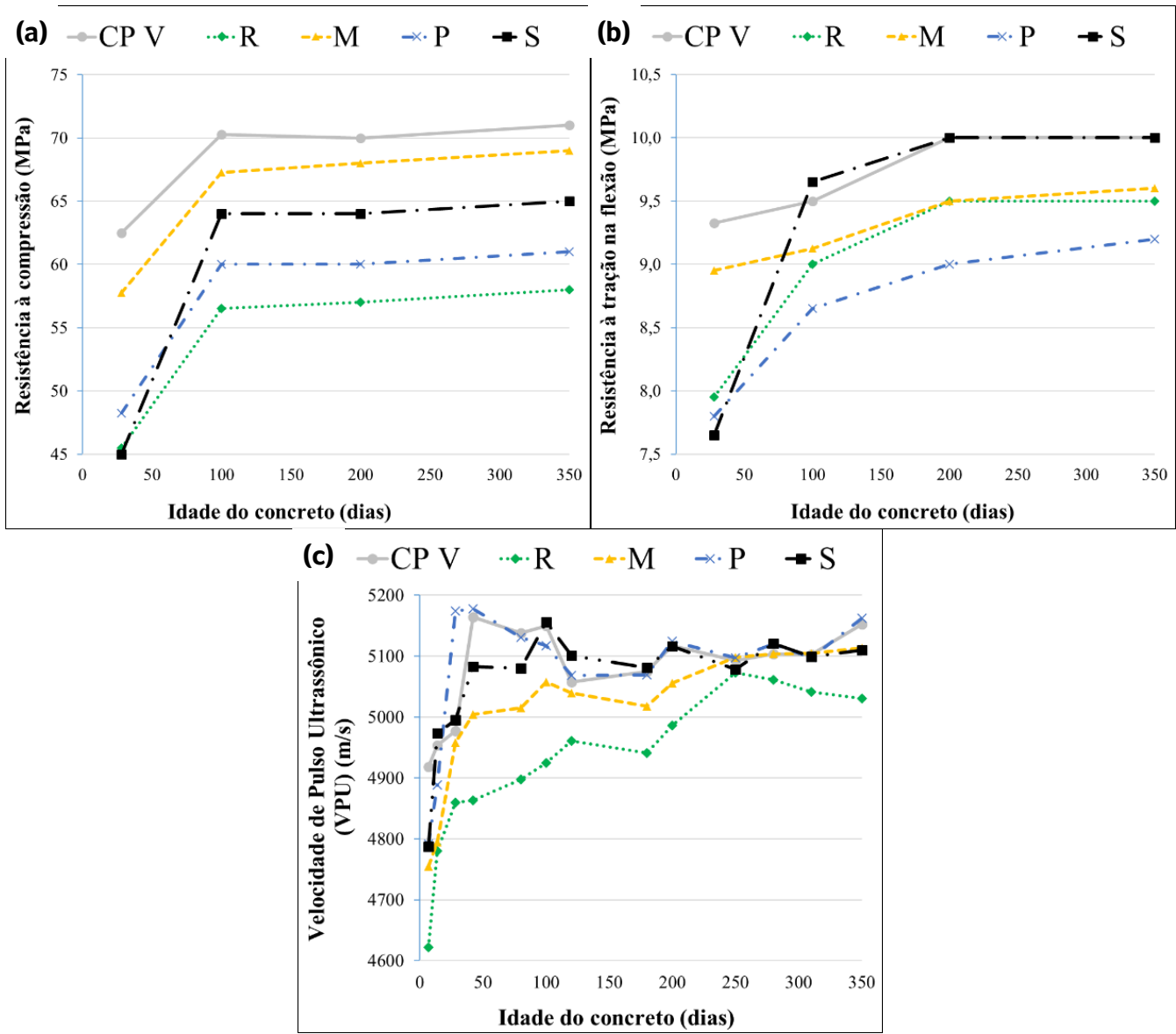

Figura 4 - Ensaios de caracterização nas idades iniciais de hidratação dos cinco diferentes concretos imersos em tanque com água saturada com cal à temperatura ambiente.

Legenda: CPV - somente cimento CPV sem adição; R - Referência; M e P - produtos comerciais; $S$ - Solução de silicato de sódio neutro. 
Como já era esperado, o concreto CP V foi o que teve as maiores resistências mecânicas aos 28 dias, pois de acordo com Mehta e Monteiro (2014) os concretos sem adições minerais no cimento e com níveis de clínquer superiores a 90\% (CP V) ganham aproximadamente $90 \%$ da resistência aos 28 dias de cura úmida. Por outro lado, os concretos com adições pozolânicas reagem mais lentamente e por isso somente atingem cerca de $90 \%$ da sua resistência mecânica após os 91 dias de cura. Também vale ressaltar que o $\mathrm{CP} V$ se caracteriza pela expressiva finura do aglomerante, o que acelera as reações iniciais do cimento principalmente nos primeiros 7 dias, sendo natural que o concreto com somente $C P$ $\checkmark$ apresente valores iniciais mais altos também para a VPU em relação a todos os outros concretos.

Pode-se observar também que a adição de cristalizantes foi benéfica às características mecânicas do concreto, pela densificação da matriz cimentícia causada pela possível formação de produtos de cristalização no interior dos poros. Tal constatação é corroborada pela Fig. 4A e Fig. 4C, onde todos os espécimes com adição de cristalizante apresentaram maior resistência à compressão e velocidade de pulso ultrassônico ao longo do tempo se comparados com a série de referência (R).

\subsection{Degradação do concreto atacado por ácido sulfúrico}

Após 300 dias de exposição dos cinco diferentes concretos aos dois ambientes agressivos, era nítido o processo de desagregação superficial, apresentando-se como uma espécie de descamação, sendo possível sua remoção com as mãos (Fig. 5). Essa forma de deterioração por descamação também foi registrada como presente nos trabalhos de Hoppe Filho et al. (2014); Capraro et al. (2019) e Godinho e Medeiros (2021), onde os autores avaliaram a exposição do concreto em condições reais em Estações de Tratamento de Esgoto. Pode-se notar a presença de uma superfície branco-acinzentada, que também foi reportada por Taheri et al. (2020) em testemunhos de concretos extraídos de tubos de esgoto como sendo sinais de corrosão do concreto por ataque ácido. Além disso, também pode-se verificar a rápida alteração na porosidade e mudança na coloração da superfície do concreto, que também foi reportado por Silva et al. (2018) em corpos de prova de argamassa submersos em solução de ácido sulfúrico preparada em laboratório.

\section{Tanque com ácido}
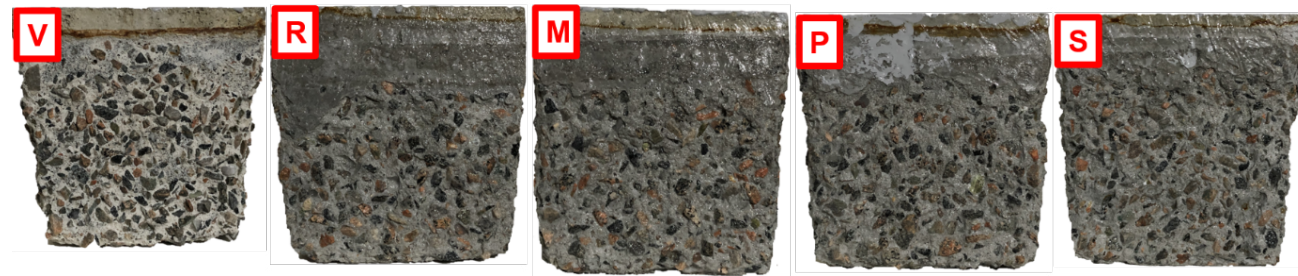

Canaleta da ETE
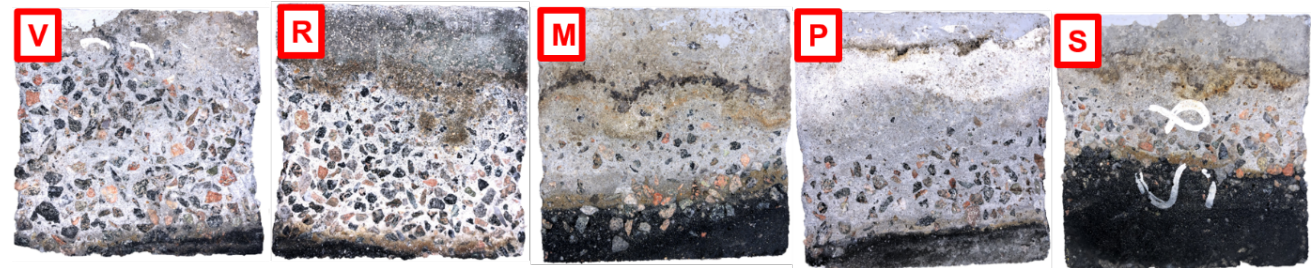

Figura 5 - Corpos de prova dos cinco diferentes concretos após 300 dias de exposição à solução de ácido. Legenda: CPV - somente cimento CP V sem adição; R - Referência; M e P - produtos comerciais; $\mathrm{S}$ - Solução de silicato de sódio neutro. 
Essa descamação superficial visualizada na Fig. 5 resultou em uma perda de massa contínua de todos os concretos (Fig. 6). Também foi possível calcular a velocidade com que essa degradação ocorria (Tabela 3) em virtude da diminuição das dimensões dos corpos de prova de concreto.
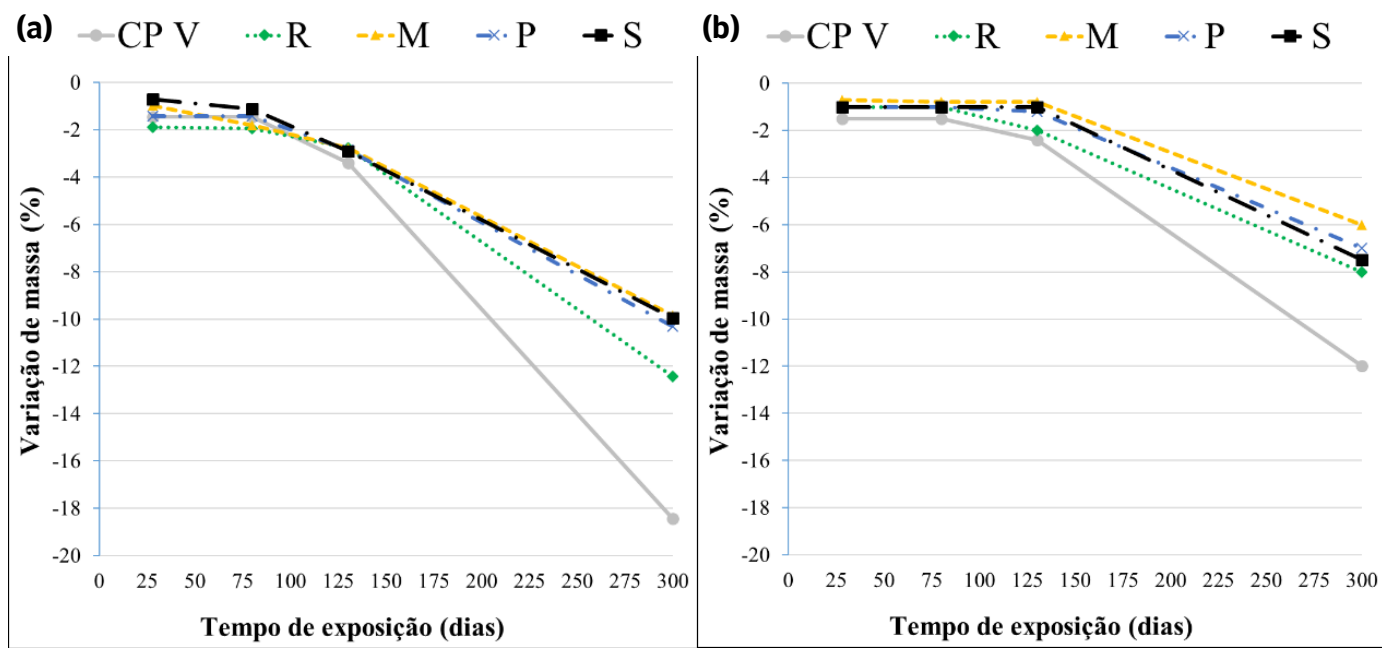

Figura 6 - Variação de massa dos cinco diferentes concretos nos dois ambientes agressivos. a - Tanque com solução de ácido sulfúrico; b - Canaleta da ETE.

Legenda: CPV - somente cimento CP V sem adição; R - Referência; M e P - produtos comerciais; S - Solução de silicato de sódio neutro.

Tabela 3 - Velocidade de degradação dos cinco diferentes concretos nos dois ambientes agressivos.

\begin{tabular}{|c|c|c|c|c|c|}
\hline \multirow{3}{*}{ Local da leitura } & \multicolumn{5}{|c|}{ Tanque com solução de ácido } \\
\hline & \multicolumn{5}{|c|}{ Velocidade de degradação (mm/mês) } \\
\hline & CPV & $\mathbf{R}$ & $M$ & $\mathbf{P}$ & $\mathbf{S}$ \\
\hline Topo & 0,90 & 0,55 & 0,30 & 0,65 & 0,55 \\
\hline \multirow[t]{2}{*}{ Base } & 1,05 & 0,60 & 0,35 & 0,75 & 0,60 \\
\hline & \multicolumn{5}{|c|}{ Canaleta da ETE } \\
\hline $\begin{array}{l}\text { Zona de molhagem e } \\
\text { secagem }\end{array}$ & 0,55 & 0,45 & 0,25 & 0,55 & 0,50 \\
\hline Zona submersa & 0,25 & 0,15 & 0,10 & 0,15 & 0,15 \\
\hline
\end{tabular}

Legenda: CPV - somente cimento CP V sem adição; R - Referência; M e P - produtos comerciais; $\mathrm{S}$ - Solução de silicato de sódio neutro.

Em relação aos concretos do tanque com solução de ácido, a perda de massa e velocidade de degradação estão diretamente relacionadas e foi clara a influência da adição de cinza volante na redução desses dois parâmetros. Os concretos com cinza volante tiveram até $33 \%$ menos de perda da massa e também perderam em média aproximadamente $4,5 \mathrm{~mm}$ a menos da camada de concreto superficial na base do corpo de prova, ao final dos 300 dias de exposição, quando comparados ao concreto CP V.
Pesquisas de outros autores indicaram valores inferiores de velocidade de degradação, pois, de acordo com Monteny et al. (2000), a corrosão por ácido sulfúrico de origem biogênica fica dentro de uma faixa em torno de $0,08 \mathrm{~mm} / \mathrm{mês}$ a 0,42 $\mathrm{mm} / \mathrm{mês}$. Gu et al. (2018), realizando testes com várias metodologias de degradação e utilizando um concreto com cimento comum (OPC), que é similar ao $\mathrm{CP} V$, com relação água/aglomerante de 0,7 e resistência à compressão de $36,4 \mathrm{MPa}$ aos 28 dias de cura, observaram aproximada- 
mente 1,26 $\mathrm{mm}$ e $3 \mathrm{~mm}$ de profundidade de corrosão após 112 dias de exposição a uma solução de $1 \%$ de ácido sulfúrico. Convertendo esses valores para a velocidade de corrosão em $\mathrm{mm} /$ mês, obtêm-se aproximadamente $0,31 \mathrm{~mm} / \mathrm{mês}$ e $0,75 \mathrm{~mm} / \mathrm{mês}$, respectivamente. De Belie et al. (2002) também utilizaram um concreto com cimento OPC e relação água/aglomerante de 0,4 , e após 2 meses de experimento exposto a uma solução de 0,5\% de ácido sulfúrico, observaram uma profundidade máxima de corrosão de $0,4 \mathrm{~mm}$, equivalente a $0,2 \mathrm{~mm} / \mathrm{mês}$ de velocidade de degradação.

Pode-se notar, nos concretos dentro do tanque com solução de ácido, que a velocidade de degradação é maior na base do que nos topos, o que pode indicar mais concentração de ácido e/ou acúmulo de enxofre no fundo do tanque e pouca influência da concentração de oxigênio nesse tipo de processo, pois a concentração de $\mathrm{O}_{2}$ é maior na interface ar/líquido, do que no fundo do tanque.
Em relação aos concretos da ETE, pode-se notar que a zona de molhagem e secagem possui uma maior degradação, justamente pela influência significativa da concentração de oxigênio nesse processo de deterioração biológica. As oscilações horárias do nível do esgoto da ETE criam uma região úmida, mas não saturada, que, aliada com a temperatura adequada e outros fatores, fazem com que as bactérias do gênero Thiobacillus sp. se proliferem. Neste processo, elas convertem o enxofre elementar a ácido sulfúrico de maneira mais eficiente, fazendo com que essa região tenha uma concentração maior do agente agressivo (EŠTOKOVA et al., 2012; GUTIERREZ-PADILLA et al., 2010; MONTENY et al., 2000). Portanto, a deterioração do concreto na zona de molhagem e secagem é mais agressiva do que nas demais regiões.

$\mathrm{Na}$ Fig. 7 é apresentada a avaliação visual, e na Tabela 4, os valores médios do ensaio de profundidade de neutralização dos cinco diferentes concretos nos dois ambientes agressivos.

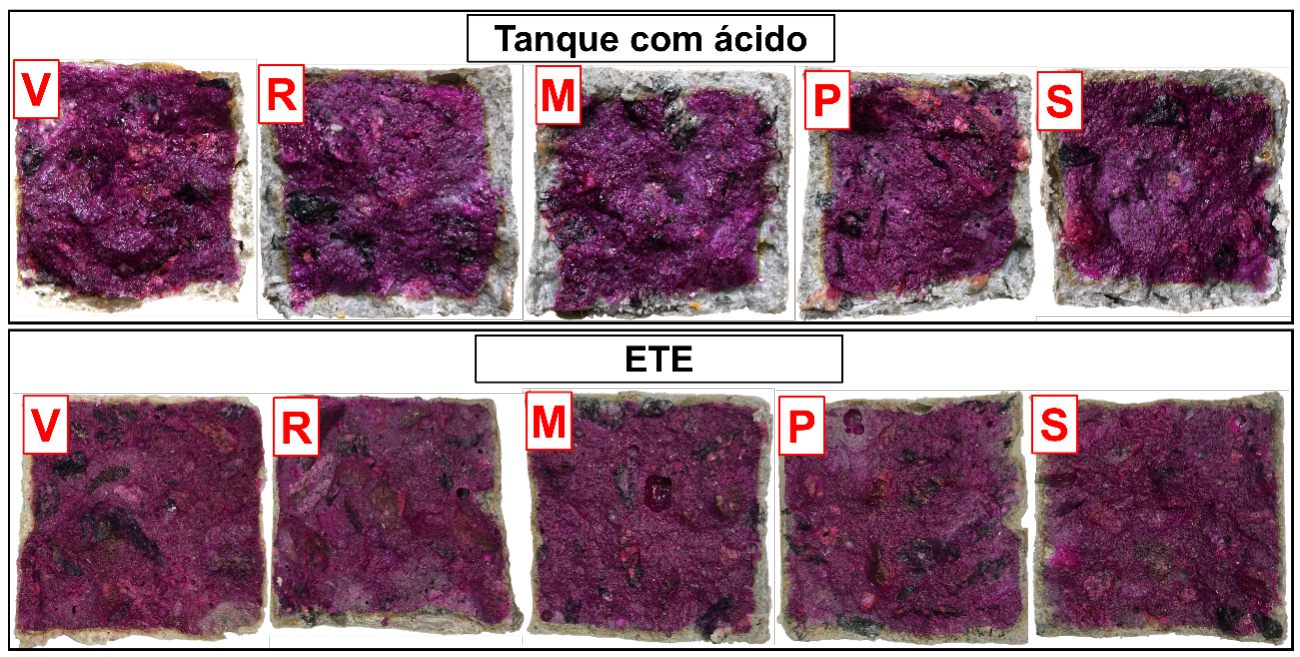

Figura 7 - Profundidade de neutralização dos cinco diferentes concretos nos dois ambientes agressivos após 300 dias de exposição.

Legenda: CPV - somente cimento CP V sem adição; R - Referência; M e P - produtos comerciais; $\mathrm{S}$ - Solução de silicato de sódio neutro. 
Tabela 4 - Profundidade de neutralização dos cinco diferentes concretos nos dois ambientes após 300 dias de exposição.

\begin{tabular}{|c|c|c|c|c|}
\hline \multicolumn{5}{|c|}{ Tanque com solução de ácido } \\
\hline \multirow{2}{*}{ Local da leitura } & \multicolumn{4}{|c|}{ Profundidade de neutralização (mm) } \\
\hline & 28 dias & 80 dias & 130 dias & 300 dias \\
\hline $\mathrm{CPV}$ & 0,5 & 1 & 1,5 & 2,5 \\
\hline $\mathrm{R}$ & 0,5 & 0,8 & 2,6 & 3,6 \\
\hline M & 0,5 & 0,7 & 2,5 & 3,5 \\
\hline $\mathrm{P}$ & 0,5 & 0,8 & 2,6 & 3,6 \\
\hline $\mathrm{S}$ & 0,5 & 0,7 & 2,5 & 3,5 \\
\hline \multicolumn{5}{|c|}{ Canaleta da ETE } \\
\hline CPV & 0,0 & 0,2 & 0,7 & 1,8 \\
\hline $\mathrm{R}$ & 0,0 & 0,3 & 0,8 & 2,6 \\
\hline M & 0,0 & 0,4 & 0,9 & 2,5 \\
\hline$P$ & 0,0 & 0,3 & 0,8 & 2,6 \\
\hline$S$ & 0,0 & 0,2 & 0,7 & 2,5 \\
\hline
\end{tabular}

Legenda: CPV-somente cimento CPV sem adição; R-Referência; M e P-produtos comerciais; S-Solução de silicato de sódio neutro.

Observando a Tabela 4 e avaliando principalmente os valores finais após 300 dias de exposição, ocorreu um falso negativo com este ensaio, pois o concreto $\mathrm{CP} \vee$ apresentou os menores valores. Porém, isso correu em virtude da descamação superficial elevada e maior velocidade de degradação que o CP V teve em relação a todos os outros concretos, fazendo com que a camada neutralizada desagregue, não sendo contabilizada no ensaio com a aspersão de fenolftaleína e medição com o paquímetro.

Vale ressaltar também que a velocidade com que o ácido penetra no interior do concreto é influenciada principalmente por essa "barreira de concreto deteriorado" que, de acordo com Monteny et al. (2000), é composta em grande parte por gipsita.

Deste modo, esse ensaio não pode ser utilizado de forma individual para a avaliação da deterioração do concreto submetido ao ataque por ácido sulfúrico por longos períodos, pois pode gerar interpretações equivocadas.

Como pode ser observado na Fig. 8, as amostras expostas ao ácido sulfúrico químico tiveram uma redução ligeiramente maior na resistência à compressão, o que, de acordo com Erbektas et al. (2020), pode ser explicado pelo fato de a desestabilização e a descalcificação das fases endurecidas das amostras serem mais prejudiciais do que a formação de gipsita e etringita devido a reações químicas.

Ao final dos 300 dias de exposição, o concreto CP V apresentou a maior resistência à compressão em relação a todos os outros com adições, e isso se justifica pelo fato de a região interna do concreto estar intacta e sofrer pouca influência do processo de deterioração. Avaliar somente as resistências mecânicas também poderia gerar interpretações equivocadas, pois, como foi mostrado nos ensaios de velocidade de degradação e variação de massa, o concreto CP V foi o que mais sofreu com o ataque ácido e apresentou menor durabilidade frente a esses ensaios. Pode-se constatar que os 300 dias de exposição foram insuficientes para que a perda de massa tivesse maior influência nos ensaios mecânicos. Isso porque se a exposição fosse por um período mais longo, em um determinado tempo o corpo de prova teria perdido massa suficiente para que os valores de resistência mecânica diminuíssem de forma significativa, fazendo com que o concreto CP V tivesse as menores resistências se comparado com os demais concretos. 

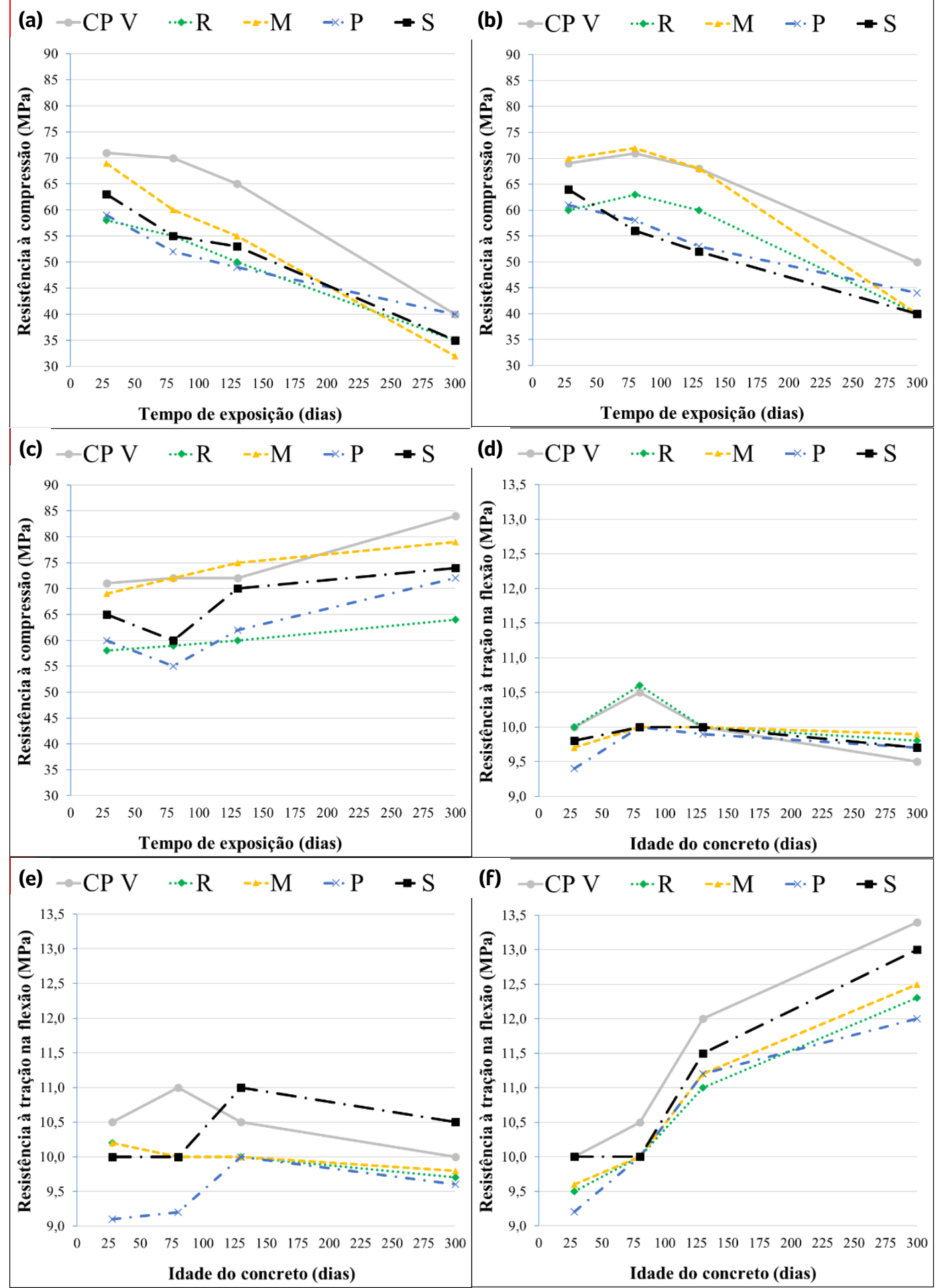

Figura 8 - Ensaios mecânicos dos cinco diferentes concretos ao longo do tempo. Resistência à compressão uniaxial: a - Tanque com solução de ácido sulfúrico; b - Canaleta da ETE; c - Tanque com água com cal. Resistência à tração na flexão: d - Tanque com solução de ácido sulfúrico; e - Canaleta da ETE; f - Tanque com água com cal. Legenda: CPV - somente cimento CPV sem adição; R - Referência; M e P - produtos comerciais; S - Solução de silicato de sódio neutro.

Na Fig. 9 é apresentada a velocidade de pulso ultrassônico dos corpos de prova submetidos aos três diferentes ambientes de exposição. 

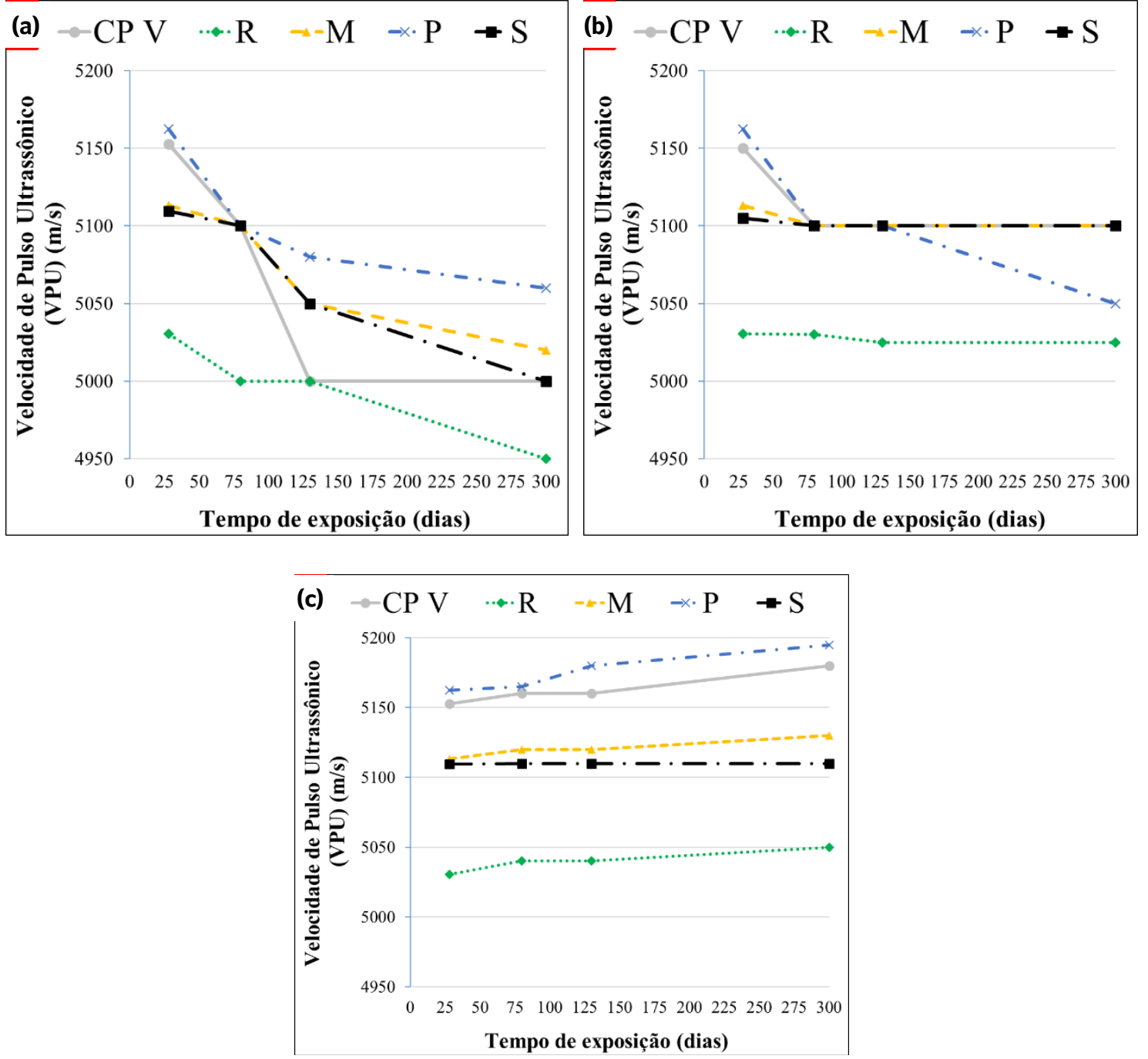

Figura 9 - Velocidade de Pulso Ultrassônico dos corpos de prova submetidos aos três diferentes ambientes de exposição. a - Tanque com solução de ácido sulfúrico; b - Canaleta da ETE; c - Tanque com água com cal. Legenda: CP V - somente cimento CP V sem adição; R - Referência; M e P - produtos comerciais; $S$ - Solução de silicato de sódio neutro.

O ensaio de VPU foi eficaz para medir a deterioração dos concretos submetidos ao ataque ácido, por mais que esse ataque tenha ocorrido em uma fina camada de no máximo $2 \mathrm{~cm}$, como observado no ensaio de velocidade de deterioração, que mediu a diminuição das dimensões dos corpos de prova. Essa diminuição da VPU dos concretos expostos aos ambientes agressivos se deu principalmente pela perda do contato homogêneo e retilíneo entre a superfície dos eletrodos e a superfície do concreto deteriorado, o que acaba dificultando a passagem do pulso através do interior do concreto.

\section{CONCLUSÕES}

Diante de todos os resultados observados, pode-se concluir que:

- De modo geral, a degradação dos concretos no tanque com ácido foi maior do que na canaleta da ETE, pois no ambiente de laboratório a maioria das condições que tiveram grande influência na degradação foram controladas e mantidas constantes, como a concentração do agente agressivo e o nível do líquido dentro do tanque; 
- Para os concretos em ambiente de laboratório, dentro do tanque com solução de ácido sulfúrico, a velocidade de deterioração é maior na base do que no topo;

- Em relação aos concretos expostos na ETE, a zona de molhagem e secagem possui uma maior degradação, pela influência significativa da concentração de oxigênio nesse processo de deterioração biológica;

- A velocidade de deterioração e a perda de massa são os meios de avaliação mais confiáveis para avaliar a durabilidade a longo prazo de estruturas de concreto exposto ao ácido sulfúrico;

- A velocidade de deterioração e a perda de massa são menores nos concretos com adições de cinza volante, cristalizantes comerciais e solução de silicato de sódio;

- O ensaio de profundidade de neutralização, quando realizado em concretos submetidos a longo prazo de exposição a ambientes agressivos, pode gerar falsos positivos e/ou negativos, o que em consequência ocasiona interpretações equivocadas;

- Os ensaios mecânicos também podem gerar interpretações equivocadas na avaliação dos concretos, pois necessitam de um maior tempo para que a deterioração seja efetiva, significativa e gere valores de resistências condizentes com a durabilidade dos concretos testados.

- O ensaio de VPU foi eficaz para medir a deterioração dos concretos submetidos ao ataque ácido.

\section{AGRADECIMENTOS}

Os autores expressam a sua gratidão às agências brasileiras CNPq, Capes e Fundação Araucária pela bolsa e apoio financeiro, à Universidade Federal do Paraná (UFPR) campus Curitiba, Centro Politécnico, ao Departamento de Construção
Civil (DCC), ao Programa de Pós-Graduação em Engenharia Civil (PPGEC), ao Centro de Estudos de Engenharia Civil (CESEC), ao Laboratório de Materiais e Estruturas (LAME), aos laboratórios do DACOC/NPT da Universidade Tecnológica Federal do Paraná (UTFPR) campus Curitiba, sede Ecoville, à Companhia de Saneamento do Paraná (SANEPAR), ao grupo de pesquisa de Patologia e Recuperação das Construções (PRC) e às empresas Cia. de Cimentos Itambé, Votorantim Cimentos, Buschle \& Lepper S.A, MC-Bauchemie Brasil, Penetron Brasil Ltda., Viapol Ltda. e a Lubeco Ltda., pela doação de materiais para a pesquisa.

\section{CONTRIBUIÇÃO DOS AUTORES}

Todos os autores contribuíram de forma igualitária.

\section{REFERÊNCIAS}

ABNT - ASSOCIAÇÃO BRASILEIRA DE NORMAS TÉCNICAS. NBR 13279: Argamassa para assentamento e revestimento de paredes e tetos - Determinação da resistência à tração na flexão e à compressão, Rio de Janeiro/RJ, 2005.

ABNT - ASSOCIAÇÃO BRASILEIRA DE NORMAS TÉCNICAS. NBR 5738: Concreto - Procedimento para moldagem e cura de corpos de prova. Rio de Janeiro/RJ, 2016.

ABNT - ASSOCIAÇÃO BRASILEIRA DE NORMAS TÉCNICAS. NBR 7211: Agregados para concreto - especificação. Rio de Janeiro/ RJ, 2019

ABNT - ASSOCIAÇÃO BRASILEIRA DE NORMAS TÉCNICAS. NBR 8802: Concreto endurecido - Determinação da velocidade de propagação de onda ultrassônica. Rio de Janeiro/RJ, 2019.

AMN - ASOCIACIÓN MERCOSUR DE NORMALIZACIÓN. NM 248 Agregados - Determinação da composição granulométrica. São Paulo/SP, 2003.

ASTM - AMERICAN SOCIETYFOR TESTING AND MATERIALS. ASTM C293/C293M - 16: Standard Test Method for Flexural Strength of Concrete (Using Simple Beam with Third-Point Loading). West Conshohocken, PA, USA, 2016.

ASTM - AMERICAN SOCIETYFOR TESTING AND MATERIALS. ASTM C349-14: Standard Test Method for Compressive Strength of Hydraulic-Cement Mortars (Using Portions of Prisms Broken in Flexure). West Conshohocken, PA, USA, 2014. 
BSI - BRITISH STANDARDS INSTITUTE. EN 14630: Products and systems for the protection and repair of concrete structures Test methods - Determination of carbonation depth in hardened concrete by the phenolphthalein method. v. 3, 2006.

CAPRARO, A. P. B.; CHEREMETA, M. A.; GONÇALVES, M. P. G.; CREMONEZ, C.; DE MEDEIROS, M. H. F. Influence of the cement type and water/cement ratio in concretes exposed in sewage treatment plants. Construction and Building Materials, v. 229, p. 116842, 2019. https://doi.org/10.1016/j.conbuildmat.2019.116842

DE BELIE, N.; MONTENY, J.; BEELDENS, A.; et al. Experimental research and prediction of the effect of chemical and biogenic sulfuric acid on different types of commercially produced concrete sewer pipes. Cement and Concrete Research, v. 34, n. 12, p. 2223-2236, 2004. https://doi.org/10.1016/j.cemconres.2004.02.015

DE BELIE, N.; MONTENY, J.; TAERWE, L. Apparatus for accelerated degradation testing of concrete specimens. Mater. Struct, 35 (251), pp. 427-433, 2002. https://doi.org/10.1007/BF02483147

ERBEKTAS, A.R.; ISGOR, O.B.; WEISS, W.J.; Comparison of Chemical and Biogenic Acid Attack on Concrete. ACI Materials Journal, v. 117, n. 1, 2020. http://dx.doi.org/10.14359/51720293

EŠTOKOVA, A., HARBUL'ÁKOVÁ, V.O., LUPTÁKOVÁ, A., ŠTEVULOVÁ, $N$. Study of the deterioration of concrete influenced by biogenic sulphate attack. Procedia Engineering, v. 42, n. August, p. 17311738, 2012. https://doi.org/10.1016/j.proeng.2012.07.566

GODINHO, J. P.; MEDEIROS, M. H. F. Biogenic sulfur attack in a reinforced concrete sewage treatment plant. Re-visited mechanism and rehabilitation proposal. Engineering Failure Analysis, v. 124, p. 105354, june, 2021. https://doi.org/10.1016/j.engfailanal.2021.105354

GODINHO, J. P.; SOUZA JUNIOR, T. F.; MEDEIROS, M. H. F.; SILVA, M.S. A. Factors influencing ultrasonic pulse velocity in concrete. Revista IBRACON de Estruturas e Materiais, v. 13, n. 2, p. 222-247, abr. 2020. http://dx.doi.org/10.1590/s1983-41952020000200004

GU, L.; VISINTIN, P.; BENNETT, T. Evaluation of accelerated degradation test methods for cementitious composites subject to sulfuric acid attack; application to conventional and alkali-activated concretes Cem. Concr. Compos., 87, pp. 187-204, 2018. https:// doi.org/10.1016/j.cemconcomp.2017.12.015

GUTIERREZ-PADILLA, M. G. D. et al. Biogenic sulfuric acid attack on different types of commercially produced concrete sewer pipes. Cement and Concrete Research, v. 40, n. 2, p. 293-301, 2010. https://doi.org/10.1016/j.cemconres.2009.10.002
HOPPE FILHO, J.; RHEINHEIMER, B.; KHOE, S.; ARTIGAS, L. V.; SABBAG, A. F.; MEDEIROS, M. H. F. Degradação do concreto de uma Estação de Tratamento de Esgoto (ETE) por ácido sulfúrico biogênico. Revista ALCONPAT, v. 4, p. 86-96, 2014. https://doi. org/10.21041/ra.v4i2.63

HUSNI, R. ; RINCON, O. T. ; MEDEIROS, M. H. F. ; MONTEIRO, E. C. B.; HELENE, P. Capítulo XIII.c: Prevención de problemas patológicos en construcciones específicas - Plantas potabilizadoras, Desalinizadoras y de Tratamiento de Residuos. In: Red Prevenir. (Org.). Prevención de poblemas patológicos en estructuras de concreto. 1ed. Mérida: Colaboración Interamericana en Materiales (CIAM), v. único, p. 113-145, 2012.

MEHTA, P. K.; MONTEIRO, P. J. M. Concreto: Microestrutura, Propriedades e Materiais. 2a edição ed. São Paulo, 2014.

MONTENY, J., VINCKE, E., BEELDENS, A., DE BELIE, N., TAERWE, L., VAN GEMERT, D., VERSTRAETE, W. Chemical, microbiological, and in situ test methods for biogenic sulfuric acid corrosion of concrete. Cement and Concrete Research, V. 30, No. 4, pp. 623-634, 2000. https://doi.org/10.1016/S0008-8846(00)00219-2

MONTENY, J.; DE BELIE, N.; TAERWE, L. Resistance of different types of concrete mixtures to sulfuric acid. Materials and Structures, v. 36, n. 4, p. 242-249, 2003. https://doi.org/10.1007/ BF02479618

PINTO, J.; TAKAGI, E. M. Sistemas de impermeabilização e proteção para obras de saneamento. Concreto \& Construções, n. 47, p. 73-79, 2007.

RILEM - INTERNATIONAL UNION OF LABORATORIES AND EXPERTS IN CONSTRUCTION MATERIALS, S. A. S. RILEM CPC-18: Measurement of hardened concrete carbonation depth. Materials and Structures. 21, 453-455 (1988). https://doi.org/10.1007/ BF02472327

SILVA, M. S. A.; GODINHO, J. P.; BONATTO, A. M.; ZANDONA, J. J.; LUCA, L. C. S.; MEDEIROS, M. H. F. Influência do ataque por ácido sulfúrico na variação dimensional de corpos de prova de argamassa de diferentes tipos de cimentos. REEC - Revista Eletrônica de Engenharia Civil, v. 14, p. 216-228, 2018. https://doi. org/10.5216/reec.v14i1.46111

TAHERI, S.; AMS, M.; BUSTAMANTE, H.; VORREITER, L.; BEVITT, J.J; WITHFORD, M.; CLARK, S.M. Characterizing concrete corrosion below sewer tidal levels at chemically dosed locations. Water Research, v. 185, p. 116245, 2020. https://doi.org/10.1016/j.watres.2020.116245 